\title{
Construcción social de la infancia a través de imágenes y fotografias: una entrada a la educación*
}

\author{
[Versión en español] \\ Social Construction of Childhood \\ Through Images and Photographs: an Entrance to Education \\ Construção social da infância \\ através de imagens e fotografias: uma entrada para a educação
}

Recibido marzo 30 de 2019. Aceptado agosto 1 de 2019.

\author{
Natalia Montaño-Peña** \\ https://orcid.org/0000-0002-3643-7584
}

Colombia

\section{Resumen}

, Para citar este artículo:

Montaño-Peña, Natalia (2020).

Construcción social de

la infancia a través de imágenes

y fotografías: una entrada a la educación.

Ánfora, 27(48), 67-92. DOI: https://doi.org/10.30854/anfv27.n48.2020.669 Universidad Autónoma de Manizales. ISSN 0121-6538/ e-ISSN 2248-6941
Objetivos: identificar los intereses y orientaciones de los estudios sobre las representaciones visuales y la producción de imágenes de infancia a través de objetos culturales, con especial acento en la fotografía, que se han constituido en fuentes de información en los campos de la historia, los estudios culturales

\footnotetext{
* Artículo derivado del proyecto de tesis doctoral "Construcción social de la infancia de la educación infantil en Colombia a través de la fotografía: 2006-2016". Doctorado Interinstitucional en educación, Universidad Distrital Francisco José de Caldas, Universidad Pedagógica de Colombia y Universidad del Valle; Énfasis en lenguaje y educación, Línea de investigación comunicación- educación en la cultura. Cohorte 2016-3.
}

\footnotetext{
** Magíster en Investigación Social Interdisciplinar. Licenciada en Educación Básica con Énfasis en Humanidades y Lengua Castellana. Candidata a Doctora del Doctorado Interinstitucional en Educación, Universidad Distrital Francisco José de Caldas, Universidad Pedagógica Nacional y Universidad del Valle, Cohorte 2016-3. Docente del Instituto de Humanidades, Fundación Universitaria Konrad Lorenz, Bogotá, Colombia.Correo: natamont_03@hotmail.com
} 
y la educación. Metodología: revisión documental de corte cualitativo, cuyo foco de observación se encuentra en los estudios de la sociedad y la cultura de América Latina y España durante los siglos XIX y XXI, con algunas alusiones a trabajos situados en el mundo prehispánico. Resultados: se encontró que la infancia es un asunto de interés interdisciplinar, por ejemplo, para las ciencias de la salud, especialmente la neurología, pediatría, epidemiología. También se hallaron trabajos sobre la infancia desde las ciencias humanas, ciencias sociales, la educación y las artes; en las últimas cuatro áreas de conocimiento, además de un marcado interés de los estudios en la percepción de imágenes de los niños y las niñas, predomina la inquietud por las representaciones de la infancia en la educación a través de imágenes. Conclusiones: a partir de un balance de los resultados de los estudios abordados se identifican oportunidades para investigaciones sobre la construcción social de la infancia en educación con fuentes visuales.

Palabras-clave: Infancia; Educación; Imágenes; Fotografía.

\section{Abstract}

Objective: to identify the interests and orientations of studies on visual representations and the production of childhood images through cultural objects, with special emphasis on photography, which have become sources of information in the fields of history, cultural studies and education. Methodology: a qualitative documentary review, that focusses on the studies of society and culture of Latin America and Spain during the nineteenth and twenty-first centuries, with some allusions to works located in the pre-Hispanic world. Results: childhood was found to be a matter of interdisciplinary interest, for example, for health sciences, especially neurology, pediatrics, epidemiology. There were also found works on childhood from the human sciences, social sciences, education and the arts; In the last four areas of knowledge, in addition to a marked interest of studies in the perception of images of boys and girls, there is a preoccupation with children's representations in education through images. Conclusions: from a balance of the results of the studies addressed, opportunities for research on the social construction of children in education with visual sources are identified.

Keywords: Childhood; Education; Images; Photography. 


\section{Resumo}

Objetivo: identificar os interesses e orientações dos estudos sobre representações visuais e produção de imagens da infância por meio de objetos culturais, com ênfase especial na fotografia, os quais se tornaram fontes de informação nos campos da história, estudos culturais e educação. Metodologia: revisão documental qualitativa, cujo foco está nos estudos da sociedade e cultura da América Latina e da Espanha durante os séculos XIX e XXI, com algumas alusões a obras localizadas no mundo pré-hispânico. Resultados: a infância foi considerada uma questão de interesse interdisciplinar, por exemplo, para as ciências da saúde, especialmente neurologia, pediatria, epidemiologia. Também houve trabalhos sobre a infância nas ciências humanas, ciências sociais, educação e artes; Nas quatro últimas áreas do conhecimento, além de um interesse acentuado dos estudos na percepção de imagens de meninos e meninas, há uma preocupação com as representações das crianças na educação por meio das imagens. Conclusões: a partir do balanço dos resultados dos estudos abordados, são identificadas oportunidades de pesquisa sobre a construção social da infância na educação com fontes visuais.

Palavras-chave: Infância; Educação; Imagens; Fotografia. 


\section{Introducción}

La infancia es una construcción social producto de un conjunto de discursos, narrativas y prescripciones que generan unas representaciones y prácticas con los niños y niñas en el marco de contextos socioculturales específicos (Jenkis, 1982; James y Prout, 1997; Corsaro, 1997; Gaitán, 2006). Y, en tanto construcción social, la infancia se transforma y con ella las prácticas en su entorno.

Estas transformaciones quedan registradas en objetos de la cultura que luego informan acerca de saberes y haceres de difícil acceso por otros medios (Burke, 2006; De Certeau, 1996). Por ejemplo, el sentimiento moderno de infancia (Ariès, 1987) se develó a partir de la observación y seguimiento a productos culturales que visibilizaron cómo se dibujaba en la sociedad una población no adulta; con ello, las prácticas con niños y niñas se transformaron y sus cambios quedaron registrados en objetos de la cultura que han sido y están siendo analizados para identificar tendencias, saturaciones y vacíos en las representaciones de la infancia.

El análisis y seguimiento a objetos culturales diversos ha permitido conocer, desde otras narrativas alternas a los discursos oficiales, los modos en que la infancia ha sido nombrada, representada, abordada y tratada. De este modo, objetos como la literatura, los juguetes, la pintura y la fotografía, se han constituido en fuente de información para la producción de conocimiento acerca de la infancia.

Por lo anterior, en el presente estudio de revisión documental se expone el análisis de trabajos en torno a los modos en que ha hecho presencia la infancia en el contexto español y latinoamericano, con énfasis en la imagen fotográfica y los estudios acerca de la función de las imágenes en el contexto visual en y de la educación.

\section{Metodología}

En este trabajo se reconoce la revisión documental como una metodología de investigación que implica una recuperación y sistematización documental analítica, para dar cuenta de la producción científica y académica y del conocimiento acumulado en torno a un tema (Marín y Restrepo, 2002). Su complejidad radica en la permanente clasificación, organización y categorización de los datos para enunciar la variedad en la producción. Para este proceso de revisión, en un primer momento, se implementó un trabajo de análisis bibliométrico, con herramientas estadísticas y motores de búsqueda de las bases de datos indexadas Science Direct y Scopus ${ }^{1}$, a partir de las combinaciones de palabras clave "infan-

1. Estas bases de datos se consultaron en primera medida, por ser las más grandes, por la calidad que garantizan en sus publicaciones y porque permiten acceder a los resúmenes, palabras claves y lista de referencias de los artículos cuando no permite redireccionar a las revistas o editoriales o cuando los 
cia y objetos culturales" "infancia e imágenes”; “infancia y fotografía” e "infancia, fotografía y educación” (términos en inglés y español para tener un amplio espectro de búsqueda de documentos). Esto, permitió identificar 3 elementos como puntos de partida:

a) Tendencias por áreas, sub-áreas y temas

b) Periodos de tiempo en donde había picos y caídas en el volumen de estudios con las combinaciones de palabras de acuerdo con las áreas, sub-áreas y los temas

c) Países e instituciones interesadas en los estudios sobre infancia, imágenes, fotografías y educación.

También, como parte de este primer momento de búsqueda, se analizaron los listados de referencias de los artículos de estas bases de datos para reconocer las orientaciones epistemológicas y metodológicas de los trabajos.

Luego, se inició un segundo momento de búsqueda, sistematización y análisis de documentos a partir de tres ejes: 1) imágenes de infancia; 2 ) representaciones de la infancia y 3) fotografía de la infancia en educación. Entonces, se enfocó la mirada en los trabajos producidos desde y en relación con América Latina y España publicados en las últimas 4 décadas, interesados en un amplio periodo de estudios que abarcó desde mediados del siglo XIX hasta el siglo XXI. Para este momento, se revisaron otras bases de datos y fuentes documentales digitales como ProQuest, Dialnet y Redalyc. En esta etapa, también se incluyeron trabajos en el campo de la comunicación y la gestión cultural, tesis doctorales ubicadas en repositorios digitales libros, revisiones y artículos científicos.

Los documentos encontrados fueron codificados, sistematizados y analizados a partir de unas matrices en las cuales se indagó por: a) datos generales del trabajo: área, sub-áreas, fecha de publicación; b) autor (es), filiación institucional; c) lugar y tiempo: periodo de estudios, región/país de interés; d) institución/ espacio objeto de estudio; e) objetos-representaciones-mediaciones- medios; f) objetivos del estudio; g) referentes teóricos y metodológicos; y h) resultados y conclusiones.

A través de esta matriz fue posible una observación dirigida para la categorización. Aquí, se ubicó como factor organizador y de análisis Objetos culturales-representaciones-mediaciones-medios y, de acuerdo con el volumen de trabajos en cada uno de su tipo, se pasó a analizar los alcances de los objetivos, los referentes teóricos y metodológicos, para filtrar los trabajos más relevantes según calidad de estos ítems, determinada principalmente por cumplimiento de objetivos.

trabajos no tienen Open Access. 
En este proceso, varios trabajos fueron descartados y se pasó a un tercer momento de revisión, sistematización y análisis que se adelantó de acuerdo con el factor de resultados y conclusiones se pudo llegar a la subcategorización. En este tercer momento, la revisión se complementó con la búsqueda directa en catálogos de bibliotecas para consulta de libros digitales e impresos, así como publicaciones sobre exposiciones culturales, de arte y exposiciones temporales en museos relacionadas con la infancia, la fotografía y la escuela. Con esta última búsqueda se nutrieron las sub-categorías y, con ello, las categorías de la revisión documental.

A medida que se avanzaba en la sistematización y análisis a lo largo de los tres momentos, emergieron las categorías y subcategorías que orientan y dan estructura a los resultados aquí presentados.

\section{Resultados}

Este estudio encontró que la infancia es un tema de interés de orden interdisciplinar, en el que destacan las ciencias de la salud, especialmente la neurología, pediatría, epidemiología. En menor medida, se encuentran trabajos sobre la infancia desde las ciencias humanas, ciencias sociales, la educación y las artes; en estas cuatro últimas áreas de conocimiento, entre los estudios académicos, además de haber un marcado interés en la percepción de imágenes de los niños y las niñas, predominaba la inquietud por las representaciones de la infancia en la educación de los niños y niñas a través de imágenes.

También se halló que hay un reciente interés en la producción de nuevo conocimiento acerca de la infancia y las imágenes (producción de imágenes, uso de imágenes y/o percepción de imágenes) en las últimas 3 décadas. Además, en los temas e imágenes de la infancia hay una amplia producción de conocimiento principalmente desde el Reino Unido, Australia y Norte América; desde América Latina hacen presencia en estas bases de datos, principalmente, trabajos en el campo de las artes y las ciencias sociales.

Los demás resultados del presente estudio se presentan a continuación mediante las categorías y subcategorías:

\section{Imágenes y representaciones de niños y niñas a través de la literatura, juegos, juguetes y la pintura: construcción de subjetividades}

La infancia ha sido objeto de producción y reproducción de una multiplicidad de imágenes visuales o narradas, a través de una variedad de objetos cultu- 
rales usados y apropiados en la vida cotidiana. Estos objetos, junto con los discursos oficiales e institucionales de cada sociedad y época, han narrado lo que ha significado, lo que debía ser y debía hacerse con los niños y las niñas de acuerdo con un marcado interés por moldear la subjetividad de los niños y niñas asociado con el proyecto político y económico. De este modo, los objetos culturales no solo son portadores de información acerca de las concepciones de infancia y niñez sino de las prácticas a las que ha habido lugar con y hacia los niños y niñas.

En el abordaje de la infancia y sus representaciones, resultan relevantes dos estudios para la comprensión de la infancia moderna en la cultura occidental, que se gesta en el marco de unas necesidades y sentires de sociedades específicas; se trata del trabajo de De Maus (1982) y Ariès (1987). De Maus, rastreó la historia de la infancia desde el mundo antiguo a través de fuentes textuales y pictóricas y develó que en las culturas se ha buscado reproducir el modelo de niños y niñas ideales y en ese ejercicio el cuerpo infantil ha sido objeto de maltrato y dolor.

Por su parte, Ariès (1987), centró su interés en el arte y en las representaciones visuales del niño en el Antiguo Régimen, encontrando que por años los niños y niñas pasaron desapercibidos y sólo hasta los siglos XVII y XVIII ocuparon un lugar propio, fenómeno asociado con el despertar del "sentimiento de la familia”. Este autor también exploró artefactos como el vestuario, los útiles escolares y los juguetes, para analizar cómo la transformación en los modos de representar a los niños y niñas impregnó diferentes aspectos de la sociedad en los cuales se reafirmó la presencia de la infancia.

En el contex to latinoamericano, objetos como la pintura rupestre y la iconografía prehispánica han permitido comprender prácticas contemporáneas con la infancia latinoamericana. Ardren y Hutson (2006) y Baxter (2008), exploraron la presencia y experiencias de la infancia prehispánica en las sociedades mesoamericanas y, a la vez, exponen y proponen diferentes métodos para el abordaje arqueológico en la cultura material. Igualmente, en etnohistoria y en el campo sociológico, historiográfico e incluso de historia social y cultural interesados también en este periodo de tiempo y en la época colonial, Díaz-Barriga (2012, 2013), Rodríguez (2007) y Ares-Queija (2007), centran su interés en la infancia mexicana y peruana e incluyen en sus trabajos las reflexiones en torno a las prácticas con la infancia a partir de sus representaciones iconográficas.

En sintonía con estas posibilidades de estudios a través de objetos visuales, la revisión aquí expuesta, sin alejarse del interés por la imagen, incluye el tránsito por objetos culturales desde los cuales se podría rastrear la construcción social de la infancia en diferentes épocas y sociedades. Se inicia con los resultados acerca de la producción de estudios que exploran la imagen de la infancia narrada a través de la literatura, luego se pasa a las representaciones y construcciones 
infantiles a través de los juegos y los juguetes y, posteriormente, se presentan los resultados de los trabajos que abordan la imagen de infancia.

\section{Imágenes de la infancia en la literatura: entre ideales y realidades}

En esta revisión documental se pudo evidenciar un marcado interés en indagar a través de los relatos, letras y producciones literarias latinoamericanas, los modos en que se ha creado una imagen colectiva de la infancia y cómo se ha recreado la figura de los niños y las niñas en estas sociedades. Algunos investigadores se han encargado de revisar obras literarias, obras insignia y otras obras de las sombras de la literatura latinoamericana, para caracterizar y analizar unos cambios y transformaciones en los imaginarios acerca de la infancia y en los modos de percibir a los niños y niñas. De igual manera, es posible conocer, desde los estudios de estas narrativas, acerca del lugar que ocupan estos niños y niñas en los proyectos de nación.

En el campo de la literatura latinoamericana contemporánea, la infancia ha hecho presencia en dos vías: como sujeto a quien va dirigida la obra y como personaje. En cada caso, se ha perfilado a partir de unos patrones sociales y culturales que permiten al lector acceder a una imagen de lo que es ser niño o niña o lo que significa la infancia en una sociedad. Por ejemplo, Londoño y Londoño (2012) ilustran las trayectorias de la literatura infantil colombiana y sus desarrollos en cuanto a gráfica y narrativa, que dan cuenta de los cambios en la representación de los niños y niñas entre finales del siglo XIX y la primera parte del siglo XX. La recreación del personaje fantástico y maravilloso posicionó a los niños colombianos como sujetos lectores, capaces de disfrutar la estética literaria mientras eran moldeados a través de las fábulas y rimas, en el marco de los preceptos sociales y culturales de la época.

Sobre la imagen recreada en la literatura colombiana, Robledo (2007) encuentra una transformación en la concepción de los niños y niñas entre 1920 y 1930 -transformación acompañada del proceso de modernización del país- a partir de la presencia de personajes infantiles habitantes de la calle, abandonados, despreciados por la sociedad, maltratados. A juicio de la autora, estas imágenes de la infancia hablan, a su vez, de niños y niñas independientes, incluso, emancipados de las imposiciones de los hombres adultos, porque en medio de sus trágicas circunstancias tienen la oportunidad de tomar sus decisiones y desafiar su suerte.

En relación con la mirada adulto-céntrica a la infancia y sus experiencias, se encuentra el trabajo de Donoso (2007) sobre la obra Cartucho de Nellie Campobello -pieza de la literatura que recrea la violencia durante la revolución mexi- 
cana- en donde identifica la presencia de una mirada a la infancia "doblemente marginal", al tratarse del relato de una niña que narra desde su memoria una imagen mental, íntima, un retrato-oral, una imagen-texto del recuerdo. En este trabajo, aborda el vínculo entre verbalidad y visualidad lograda través de la voz infantil, de manera que la narración se completa y se hace imagen en la mente del lector:

En general, cada relato del texto de Campobello está estructurado a partir de la figura de un personaje, la anécdota que se narra es mínima y la voz infantil neutraliza la carga moral de los hechos narrados. Todas estas características conspiran hacia un acto verbal que se vincula a la visualidad. Más que narración hay exposición. Más que acciones hay presentación de hechos (Donoso, 2007, p. 2).

En el caso chileno, destaca en el trabajo de Amaro y Arecheta (2014) el análisis de la producción literaria del país durante la primera mitad del siglo XX y encuentran que la experiencia infantil chilena ha sido representada en tres orientaciones muy distintas: los niños y niñas ciudadanos ideales, o la representación del "nosotros" en la sociedad en proceso de modernización; los niños del hambre, que trata de niños y niñas en condiciones precarias que salen del modelo ideal de infancia y deben lugar por mantenerse vivos; la infancia en las sombras, que da cuenta de las experiencias de la infancia que desde la esfera íntima de la familia, principalmente, y según roles de género, manifiesta críticas al orden social contemporáneo. Estas tres perspectivas abordadas en la narrativa dan cuenta de unas transformaciones no solo en la mirada a la infancia sino en la trayectoria de sus experiencias hechas relato.

Así mismo, los trabajos de Guerrero-Valenzuela (2010), quien aporta a la comprensión las diferentes maneras de vivir la infancia, en tanto se trata de una representación marginal en un mundo gobernado por adultos, ubicada en los planos de la memoria y del lenguaje, atravesada por la nostalgia de un legado mudo al que hay que devolver la palabra; sin embargo:

La infancia bien puede ser ese secreto que es necesario descifrar o interpretar en busca de un sentido para un presente a menudo precario e incompleto, revuelto y en crisis. Entendida como herencia, la infancia forma parte de una genealogía discontinua, abstracta, inasible y cambiante según las operaciones de la memoria, cuyos vaivenes siempre son inestables y frágiles, no lineales ni exactos. Representada desde la adultez, es un saber que fracasa en la medida en que no acumula conocimientos, sino que, al adquirirlos, los pone bajo sospecha. De esa operación, empero, se obtiene la certeza de su imposibilidad, entendida como 
una promesa que es viable renovar, justamente, a través de su incumplimiento

(Guerrero-Valenzuela, 2010, p. 7).

A través de la literatura latinoamericana se revela una imagen de la infancia polarizada: por un lado, está el retrato de la infancia añorada, idealizada, al representar la sociedad adulta en potencia y encarnar la memoria de la infancia vivida y/o añorada; y, por otro, presenta una imagen de la infancia indeseada, la infancia carente, maltratada, la que no debería hacer presencia, pero que se cuela en la narrativa. No obstante, es importante señalar cómo a través de la literatura, América Latina ha representado y verbalizado la inconformidad con las instituciones y los regímenes de poder a través de la figura de los niños y niñas militantes o agentes en contextos de conflicto social, ya sea desde la revolución o desde sus sentires en la vida privada.

\section{La infancia en los juguetes y los juegos: construcción de la imagen infantil de la obediencia y el consumo}

Los juegos y los juguetes son símbolo de la experiencia infantil y constituyen un objeto de estudio abordado en diferentes disciplinas y campos del conocimiento (antropología, filosofía, historia de la cultura, psicología y arte), que reconocen en ellos constructos socio-culturales que dan cuenta de la historia de la infancia y la memoria de la infancia, personal y colectiva. A su vez, se han reconocido como la huella que han dejado los niños y niñas en diferentes sociedades y que dan cuenta la evolución de la humanidad y su capacidad creadora (Benjamin, 1987, 1989; Ridao y Montenegro, 2014).

En el contexto latinoamericano, se encuentran estudios orientados a la comprensión de la relación entre los juegos y los juguetes con el entramado social, político y cultural. Al respecto, Londoño y Londoño (2012) analizan los cantos, rondas infantiles y juguetes de los niños y niñas colombianos, entre mediados del siglo XIX y la primera mitad del siglo XX, para poner en evidencia la estrecha relación entre estos objetos y estrategias de docilización del cuerpo infantil.

En el campo de la educación y la pedagogía en Colombia, Cárdenas (2012) problematiza la aparente asociación natural entre la infancia, los juegos y los juguetes con el fin de develar los modos en que, a mediados del siglo XX, se implementaron estos objetos dentro y fuera de las escuelas para la corrección, producción y reproducción de subjetividades en los niños y niñas, de acuerdo con el ideal de ciudadano.

Cárdenas halla en la sociedad colombiana de 1930 a 1960 una valoración -soportada en saberes disciplinares- al juego para el control del estado físico, in- 
telectual, afectivo y moral de la población infantil y, al juguete, como medio para la formación de padres y madres de familia moderna. Así, los juegos y juguetes pueden identificarse como los artefactos culturales de la época que contribuyeron a la incorporación de unos modelos de ver, nombrar e intervenir a la infancia.

Los juegos y los juguetes no solo se incorporaron en la escuela para moldear subjetividades, sino que llegaron a los hogares latinoamericanos para forjar otros sujetos útiles a la sociedad y la economía de los países en proceso de modernización: niños y niñas como sujetos consumidores.

En el campo de la historia cultural y social se encuentra el trabajo de Sosenski (2012), sobre consumo infantil y juguetes en México entre los años 50 y 60 del siglo XX, periodo en el cual se le adjudicó al juguete funciones de cuidado y educación que condujeron al consumo infantil caracterizado por: a) circulación por diferentes medios de información y comunicación del juguete como proveedor de felicidad; b) el plástico y la importación como valores intrínsecos al juguete; c) preocupación acerca del uso de juguetes bélicos; d) la reproducción de roles de género. En este proceso, se evidencia cómo a través de diferentes medios se construyó una imagen de niños y niñas como agentes empoderados en una sociedad en vía de desarrollo y urbanización, de crecimiento económico y modernización, todo para la persuasión del consumo.

Por último, Duek (2012) ubica a los juegos y los juguetes en la intersección entre la cultura (integrando allí sus condicionamientos y posibilidades) la trayectoria social y educativa de quienes juegan y la historia en la que esa práctica se desarrolla.

Ahora, los estudios sobre la relación entre infancia, cultura, juegos y juguetes demuestran que los objetos creados para el goce y disfrute de los niños y niñas no son ajenos a intereses específicos de producción de subjetividades dentro y fuera de las instituciones de socialización de la infancia como lo son, para este caso, la familia, la comunidad y la escuela. Por lo anterior, se pusieron en circulación imágenes de infancia que narraban la necesidad de moldear el carácter de los niños y niñas a través de los usos que ellos daban a artefactos de la cultura para su recreación; del mismo modo, se reprodujo, en los periodos objeto de los estudios, la visualización de los niños y niñas como sujetos de consumo, foco de la industria de la recreación y el entretenimiento.

Por eso, mientras que a través de la literatura se narraba una infancia en tensión entre el ciudadano ideal y el ciudadano indeseado (aquel en situación precaria) también se registraban las experiencias de niños y niñas agentes de cambios estructurales aun cuando estaban bajo regímenes adulto-céntricos. Es decir, a través de los juegos y los juguetes las imágenes de infancia son las de los futuros ciudadanos útiles para las industrias de consumo que se producen a 
través de objetos desde las escuelas y la producción de sujetos consumidores en la seguridad de los hogares y la comunidad.

\section{Imágenes de la infancia en la pintura: niños y niñas en el paisaje visual}

A diferencia de los anteriores objetos culturales, la pintura, en tanto propuesta estética visual, introduce en el panorama cultural una representación más directa, tangible y aprehensible de la infancia; esto es, como foco de múltiples interpretaciones desde el uso de marcos de saberes, creencias y experiencias de los espectadores. De la revisión documental se destacan tres trabajos de investigación que buscan analizar las relaciones que teje la comunidad con dos tipos de pinturas icónicas en la cultura.

Los trabajos de Jiménez (2012) y Cardona-Quitián (2014) toman como referente la imagen del Divino Niño Jesús, una pieza de arte religioso representativa en la cultura bogotana y analizan la movilización de prácticas individuales y colectivas de una ciudad entera. Los investigadores encuentran en esta imagen una representación de la naturaleza, pureza y divinidad de la infancia que, a pesar de sus trasformaciones y actualizaciones, seguiría presente en diferentes obras de arte y creaciones culturales para dar cuenta de una forma de experimentar la infancia (Cardona-Quitián, 2014).

Por otro lado, en relación con el arte popular argentino, Carli (2011a) encuentra una sobre-representación de la infancia en el arte. Toma como referente la obra de Antonio Berni y su personaje Juanito Laguna, y destaca en este personaje al niño-símbolo de la niñez argentina de mediados del siglo XX, imagen capaz de transmitir una memoria colectiva de la infancia. A su vez, revela el descuido de la historiografía hacia este tipo de productos para comprender la experiencia infantil en escenarios de vida precaria lograda en la obra en mención.

Sin duda, la pintura ha sido un arte revelador para la comprensión de la presencia de la infancia en los cuadros y paisajes de vida cotidiana de la sociedad. Mediante la literatura y los juegos y los juguetes, la imagen de la infancia debe ser descubierta, pero a través de la pintura, la imagen infantil parece dada, entregada a los espectadores, para ser admirada y convocar prácticas a partir de la relación imagen-receptor. Pero este receptor no es pasivo. A través de la puntura, la infancia se hace símbolo de un sentimiento colectivo y unas prácticas (religiosas o de memoria) comunales. 


\section{La infancia en la fotografía: necesidad y memoria}

En la revisión se identifica a la fotografía como un objeto potencial para el abordaje de la construcción social de la infancia. Las fotografías contienen rasgos de su contexto de creación y cumplen con funciones y usos específicos; son imágenes accesibles (Riego, 1999), percibidas colectivamente (Burck, 2009) y que, según el espectador, pueden movilizar prácticas colectivas para el cambio social (Zubero, 2016). Así, a partir de estudios que abordan la relación infancia y fotografía, se identifican dos usos a tener en cuenta:

\section{a) La fotografía de la infancia y el reconocimiento social.}

En un principio, el contenido de las fotografías estuvo estrechamente asociado a las composiciones exploradas en la pintura. La tradición del retrato continuaría a través de la captura fotográfica de finales del siglo XIX e inicios del siglo XX. Así, las primeras fotografías de niños y niñas fueron retratos. No obstante, una marcada diferencia entre el retrato pintado y fotografiado, radicaría en la accesibilidad a la autoimagen que tendrían los miembros de las diferentes clases sociales (Del Castillo-Troncoso, 2006, 2007).

Además, desde el surgimiento de esta tecnología y durante las tres primeras partes del siglo XX, difícilmente se puede desasociar la fotografía infantil de los adultos, ya sea porque estén presentes como parte de la composición o porque el niño imita su mundo (Riego, 1999). Esto, se evidencia en las fotografías de estudio donde los niños adoptaban el vestuario adulto y encarnaban escenas como el niño fumador, el niño aviador, el niño militar o la niña como dama de la sociedad o religiosa, entre otros (Riego, 1999; Villegas, 2012). Otro escenario común para la representación de la infancia desde la mirada adulta, fue la fotografía familiar de los siglos XIX y XX. Como lo revelan las observaciones de Riego (1999), los niños encajaban en una jerarquía familiar encabezada por el padre de familia y ocupaban un lugar secundario en la representación.

Hasta la segunda mitad del siglo XX, los niños ganaron un terreno propio y fueron representados como niños y no como adultos pequeños. No obstante, antes de que eso ocurriera, la fotografía de o con la infancia cumplía una función social: el retrato de los niños se relacionó con la posibilidad del reconocimiento de la familia en una imagen de sí y dotaba de estatus a quienes estuviesen allí representados. Si bien la fotografía no era tan costosa y exclusiva como el retrato pintado, sí era un objeto que hablaba de los medios económicos, las posibilidades de la familia, así como por el valor y reconocimiento para quedar grabados (Del Castillo-Troncoso, 2007). Finalmente, las fotografías de estudio, sólo permitían aparejar las clases sociales gracias al maquillaje, el vestuario, los efectos de luz y los retoques (Ortiz, 2006; Villegas, 2012; Alonso-Riveiro, 2015). 
De igual manera, se encontró que la fotografía de la infancia está en estrecha relación con la memoria de sí misma, con la evocación de la experiencia propia. Benjamin (2004) advirtió la experiencia de la infancia al admirar la fotografía de un niño que ya es adulto o que ya no está y, actualmente, diferentes investigaciones revelan variadas formas de la memoria de la experiencia vivida en o con la infancia a través de la fotografía (Villegas, 2012).

Un uso común de finales del siglo XIX y mediados del siglo XX fue el de las fotografías postmorten que, a juicio de Borrás (2010), “evocan formas de representación iconográfica, rituales establecidos, motivaciones personales, vínculos específicos, prácticas culturales que tienen que ver con la construcción social del duelo y la memoria” (p. 111). Si bien la muerte de los niños era bastante común debido a las epidemias, problemas de higiene, castigos físicos, prácticas de endurecimiento del cuerpo, etc., este tipo de fotografía era una manera de preservar en la memoria material familiar, una huella del niño que estuvo y no continuaba:

La fotografía del niño que va a desaparecer para siempre, logra que su presencia sea perenne y pase a formar parte del recuerdo familiar que se guarda en el álbum. Un libro gráfico que ocupará un lugar central en el salón familiar, como recordaba Walter Benjamin en uno de sus textos, y que algunas veces se abrirá para contemplar a quienes comparten el vínculo social de la familia (Riego, 1999, p. 5).

Otra experiencia de la memoria a través de la fotografía de la infancia, se encuentra en los contextos de conflicto armado y de guerra. Alonso-Riveiro (2015) trabaja con fotografías familiares españolas, producidas durante el primer franquismo; en ellas, identifica y describe anacronismos con la pretensión de representar y (re) construir la quebrantada unidad familiar que dejó la guerra por el exilio o por la muerte de sus parientes y seres queridos. En este trabajo, la autora encuentra que la iconografía familiar española tomó distancia del resto de Europa con el propósito de fijar, a través de la ficción, la imagen de una familia completa, feliz, unida a pesar de la guerra. Allí se evidencia el uso de los recursos como el fotomontaje, para incluir a los miembros ausentes y a quienes no volverían a estar.

La socialización de fotografías que capturan escenas de catástrofes naturales o provocadas por el hombre en donde se refleje el sufrimiento y el dolor humano, imprime modos de ver, dimensionar y recordar el alcance de los hechos y estos recuerdos son reforzados cuando hay presencia de niños y niñas. Estudios adelantados por Van-Leeuwen y Worski (2002) y de Maciá-Barber (2013), analizan el papel de la fotografía para legitimar la guerra y dan cuenta de cómo la presen- 
cia de niños como víctimas y testigos de la guerra se ha convertido en requisito para despertar emociones en los espectadores.

Ambos estudios se interesan en el conflicto de Israel. Por ejemplo, Maciá-Barber (2013), evidencia cómo en la fotografía de guerra no sólo se utiliza la infancia para generar impresión visual en los espectadores, sino también el modo en que los niños y niñas son expuestos a través de medios masivos de comunicación para lograr que la audiencia recuerde el conflicto armado. Sin embargo, la abundancia de material fotográfico del horror puede generar el olvido de los acontecimientos porque se convierten en imágenes comunes.

Cada época dicta reglas sobre la forma de mirar y los contenidos de las imágenes. La memoria de la infancia a través de la fotografía cambia pausadamente de un siglo a otro, por lo cual, si a inicios del siglo XX se promovía el recuerdo de una infancia seria y disciplinada, el niño de mediados y finales de siglo será recordado como sonriente, alegre e independiente (Villegas, 2012). En contextos de catástrofes o conflictos permanentes donde las dinámicas de la vida cotidiana se alteran, la fotografía se constituye en herramienta para un fin ontológico más que por un disfrute estético; para recordar, re-construir y acercarse a la experiencia de los otros.

\section{b) Transformación del imaginario de infancia a través de la fotografía.}

A través de la observación de la fotografía y la práctica fotográfica en América Latina, es posible identificar cambios en los imaginarios de la infancia de acuerdo a sus representaciones en diferentes contextos políticos y sociales. Al respecto, Villegas (2012) analiza la antioqueña colombiana y encuentra una estrecha relación entre los modos de retratar a los niños y niñas y las imágenes circulantes del Divino Niño Jesús, una noción idealizada de la infancia en términos de religiosidad y santidad, hecho que a juicio del autor obedece a un fanatismo impreso en la sociedad.

En esta misma línea se encuentra el trabajo de Del Castillo-Troncoso (2006; 2007), quien revela aspectos importantes de la construcción social y política de la infancia mexicana durante la revolución. Este investigador trabajó con las fotografías de niños y niñas que circularon en periódicos, revistas ilustradas y otras publicaciones seriadas entre 1880 y 1920 en México, y rastreó el tránsito de una concepción idealizada y frágil de la infancia a las representaciones de niños como miembros activos en la lucha política y armada. Esta niñez mexi- 
cana, con características particulares, necesidades, en contextos de pobreza y con capacidad de involucrarse y tomar partido en asuntos políticos y sociales, es la misma niñez invisibilizada en los retratos de las familias de élite (Del Castillo-Troncoso, 2007).

Otros trabajos que revelan un cambio en las concepciones y prácticas con la infancia latinoamericana son los de Muñoz y Pachón (1988; 1991; 1996; 2002) orientados a conocer la situación de la infancia bogotana entre 1900 y 1988, a través de publicaciones seriadas producidas y puestas en circulación en la ciudad capitalina. En estos trabajos, las fotografías de los niños ilustran de formas descarnadas o idealizadas -según el contexto y el tema de las publicaciones- las diferentes situaciones por las que ha atravesado la infancia bogotana. Allí encuentran que a mediados de siglo el concepto de niñez pasó de ser una referencia polarizada entre lo demoniaco y lo divino al reconocimiento de unas cualidades y emociones, de modo que las ideas de inicios de siglo acerca del pecado y la virtud innatas fueron reemplazadas por las nociones de carácter, voluntad y desarrollo de la personalidad que llegaron a la ciudad con los discursos de la pedagogía, la psicología y la sociología.

\section{c) Función social y pedagógica de la fotografía.}

Tras un recorrido por las formas en que a través de diferentes objetos culturales se ha creado, recreado y puesto en circulación una imagen de la infancia, específicamente una imagen fotográfica, el interés se vuelca sobre reflexiones e investigaciones acerca de la función de la fotografía en relación con la educación y/o la pedagogía y la comunicación.

En primer lugar, se encuentran trabajos en el campo de historia de la educación (Sanchidrián, 2011; Villa, 2015; Comas y Sureda, 2016; Soto y Pérez, 2017) orientados a ubicar a la fotografía como elemento que ha acompañado de cerca los detalles de su materialidad, arquitectura y usos de los espacios, las particularidades de los maestros, los rasgos propios de los niños (De Freitas, 2015), así como las prácticas, rutinas, rituales y aconteceres en las instituciones escolares alrededor de los escenarios educativos que los capturan, representan, visibilizan y en ocasiones los ocultan, cumpliendo con una función documentalista de la escuela que operan en la historia como testimonio (Soto y Pérez, 2017).

Ya sea que visibilice o no, la imagen fotográfica como fuente histórico-educativa permite ampliar las preguntas de investigación y superar los trabajos descriptivos de los escenarios escolares y empezar a cuestionar las experiencias dentro de ellos, explorar otros tiempos más cercanos al presente, otros espacios diferentes a los del sistema educativo y hacer uso del potencial evocador y el componente emocional de las fotografías explorando narrativas iconográficas, 
las experiencias subjetivas de quienes acceden a las imágenes y remueven recuerdos de sus escuelas, su infancia, sus juegos aun cuando no sean ellos quienes estén en las fotos (Sanchidrián, 2011).

Otra tendencia en este grupo de estudios, se encuentra en el escenario de la memoria material escolar y bien patrimonial de la educación que complejiza y enriquece así mismo el campo de investigación en historia y educación de una nación, obligando a crear nuevos escenarios pedagógicos para la divulgación de los hallazgos (Viñao-Frago, 2012). Adicionalmente, la fotografía escolar es abordada como elemento para contribuir a la configuración de memorias colectivas una vez las fotografías se hacen públicas, es decir, circulan en la comunidad y así involucran a estudiantes antiguos y nuevos y refuerza el apoyo de los proyectos educativos de las escuelas (Comas y Sureda, 2016).

En otro campo de investigación, se pueden identificar trabajos en torno a la representación y la identidad de los sujetos de la educación a través de la fotografía. Así, se encuentra el trabajo de Carli (2011b) acerca de las memorias de la crisis social de la argentina de finales del siglo XX, en donde toma como referencia de su análisis, entre varias fotografías, la imagen de un infante con delantal de la escuela pública para revelar que el encuadre del delantal blanco y el desencuadre de la cabeza del niño se relacionan con el anonimato y la pobreza oculta de los niños que asisten a las escuelas argentinas. En relación con los maestros, se encuentra la tesis de Peñaloza (2015), quien cuestiona, a partir de un corpus de fotografías del archivo del museo de la educación Gabriela Mistral de Santiago de Chile, producidas entre 1880 y 1920, la configuración de la identidad docente en relación con la comunidad escolar chilena. Allí, el autor reconoce identidades docentes superpuestas en el marco de un proyecto de construcción de ciudadanía homogénea, para lo cual la imagen fotográfica fue una herramienta estratégica para fijar dicha identidad en los registros de la vida escolar.

El panorama de la relación entre imagen y escuela se extiende hacia los estudios de la imagen. La preocupación contemporánea acerca de la imagen y la educación en el espacio escolar se encuentra en los trabajos de Dussel (2006, 2009), quien aborda a la escuela como escenario de formación de la cultura visual, comprendida como "un conjunto de discursos visuales que construyen posiciones y que están inscritos en prácticas sociales, estrechamente asociados con las instituciones que nos otorgan el 'derecho de mirada' (Dussel, 2009, p. 181).

Dussel, observa y cuestiona el tipo de imágenes (fijas y en movimiento) que circulan en el espacio educativo, los conocimientos que dichas imágenes contienen y los efectos que éstas producen e identifica la presencia de unos regímenes visuales, una tecnología de la mirada (tecnología en el sentido foucaultiano), con poder sobre los modos en que se ha enseñado a ver, por lo cual en el escenario escolar la investigadora pone en relación dos interrogantes: ¿Qué efectos produ- 
ce una imagen? y ¿Cómo educar la mirada?, señalando que este cuestionamiento implica pensar los efectos de las imágenes en los sujetos que miran, en el contexto de una cultura visual concreta, sin perder de vista que la imagen es una práctica social (2006) y retomando a Sontag, (2003), en la imagen también es posible la construcción de un "nosotros".

Seguidamente, pensando en la mirada del docente en formación, y sus prácticas didácticas y pedagógicas con sus futuros estudiantes, Ball-llatinas, (2011) se ubica en el contexto de la formación de formadores, para presentar desde esas coordenadas el alcance de la pedagogía de la mirada. Así, afirma que con ella se busca enseñar a mirar la realidad para que sea percibida, por lo acula propone 3 modos de ver: a) la mirada empática, relacionada con la mirada desde el otro de Sontag (2003); es la mirada que implica reconocerse en el otro; b) la mirada crítica o la mirada que interroga; c) la eco-mirada, o la visualización de la tierra, de la vida para preservarla.

La pedagogía de la mirada también cuestiona la función de las imágenes. Al respecto, se encuentra la tesis de Kritki y Andrea (2014) quienes toman como objeto a la fotografía en tanto elemento de construcción simbólica de la sociedad y le atribuyen una función crítica y social, así como responsabilidad en la formación de la mirada. Para las autoras, la imagen fotográfica "debe ser comprendida como un sistema de escritura visual, pluricultural, con capas de densidades, de interpretaciones y lecturas simbólicas, es el acto de ver de nuestra sociedad actual" (Kritki y Andrea, 2014, p. 61).

Para las autoras Kritki y Andrea (2014), la imagen fotográfica “debe ser comprendida como un sistema de escritura visual, pluricultural, con capas de densidades, de interpretaciones y lecturas simbólicas, es el acto de ver de nuestra sociedad actual" (p. 61).En el caso chileno, ha sido empleada en la constitución de patrones sociales, culturales y de identidad, y con ello se ha configurado en un elemento de domesticación de la mirada, por la cual encuentra la necesidad de formar públicos a través de la pedagogía de la mirada como sistema de enseñanza de la visualidad.

La preocupación por los efectos de la imagen es común en los trabajos de educación o pedagogía de la mirada. Y esta misma preocupación es compartida por Zubero (2016), quien alude al carácter interpelante de las imágenes y, con ello, al tránsito de una acción contemplativa a la realización de un conocimiento activo, a la ejecución de una acción. Este autor toma como referencia las fotografías que narran el dolor de los demás, pero abandona la discusión del contenido de la imagen y planta su preocupación en lo que sucede en el espectador y lo que él hace, luego de contemplar una imagen del "otro". Advierte que el problema no está en la divulgación del dolor ajeno sino en la potencia que hay en el especta- 
dor para reaccionar a éste y luego identifica la necesidad de una educación de la mirada, soportada en un sentimiento ético.

\section{Conclusiones}

En Occidente, la infancia ha sido representada a través de diferentes objetos culturales que evocan aspectos sensibles del ser niño o niña en diferentes momentos y contextos. Estos registros se constituyen en objetos creados con un propósito, uso o reglas de exhibición específicas. Las investigaciones que se han encargado del análisis de estos objetos, revelan la construcción de regímenes de la mirada sobre la infancia y el mundo infantil que han incidido en los modos de ver, nombrar y tratar a los niños y niñas.

Entre la diversidad de objetos portadores de conocimientos, prácticas culturales y una memoria visual de la infancia en occidente, se encuentran obras pictóricas, literarias, diferentes tipos de narrativas textuales, vestuario, artefactos de recreación e imágenes en movimiento o fijas, análogas o digitales. Todos estos objetos son rastreables en el tiempo y pueden ser interpelados para comprender la construcción de los discursos de infancia.

En los objetos visuales, ya sea con imágenes narradas o explícitas, está representada la infancia que escapa a los ideales sociales de lo que debería ser un niño o una niña y los dispositivos de cuidado, admiración y protección de los que se debería disponer para ellos. En retratos alternos a los discursos oficiales de la infancia es más rica la búsqueda de relatos, narrativas y prescripciones de los diferentes modos de transitar la infancia en una cultura o un periodo de observación.

La fotografía ha sido valorada en estudios de corte historiográfico para develar aspectos de la vida de los niños y niñas de difícil acceso a través de fuentes documentales. Se recurre a las imágenes como fuentes complementarias. El llamado a la búsqueda de una mirada de la infancia desde otras fuentes de información es constante, aunque son pocos los trabajos que se pueden rastrear al respecto.

Las fotografías de la infancia se producen y reproducen en dos tipos de instituciones: la familiar y la escolar. Fuera de ellas los niños y niñas son fotografiados para despertar y transmitir dolor y malestar. Un buen número de estudios de la imagen de la infancia que se han referenciado en este texto aluden, de diversas maneras y sin diferencia en el producto cultural en el cual se represente a la marginalidad de la infancia, cuando estas imágenes son producidas desde el mundo adulto. 
La infancia ha sido utilizada visualmente como evidencia de fragilidad y subsistencia. En cuanto a subsistencia, se le ha tratado como un componente obligatorio para poder hablar de la configuración de una familia y para cubrir la necesidad de posicionarla; esto se pudo ver en los trabajos acerca de las fotografías familiares durante las guerras civiles españolas. Evidencia de fragilidad, es la presencia de la infancia en guerra cuando se busca narrar la magnitud de los conflictos armados.

El interés académico latinoamericano por la relación entre infancia y fotografía ha aumentado en las últimas tres décadas, más la infancia de interés de estos estudios no ha sido la infancia contemporánea. No fue posible documentar estudios que recurrieran a las fotografías para dar cuenta de la construcción social de la infancia contemporánea, aun cuando en la vida cotidiana circulan en abundancia fotografías de niños y niñas.

Al momento de hacer una búsqueda de estudios, análisis e investigaciones de este tipo de objetos para la comprensión, construcción y reconstrucción de la infancia, especialmente en el campo de la educación, la información es escasa, por lo menos en el contexto latinoamericano. No obstante, se concluye que la fotografía ha empezado a ser valorada como instrumento para conocer los escenarios y las prácticas escolares que incluyen a maestros, directivos, así como a los niños y niñas; también se le reconoce como objeto cultural pues estas fotografías constituyen un lugar importante en el patrimonio histórico y educativo de diferentes sociedades. Aun así, el volumen de trabajos es escaso a pesar de ser una institución productora de fotografías de niños y niñas.

Fuera de la escuela, pero aún en el campo de la educación, la fotografía también ha sido objeto formador a través del cual se narran los modos de transitar en una sociedad o cultura, dirigida a audiencias infantiles y adultas; es el caso de los museos y escenarios alternos de educación.

Finalmente, es importante destacar el notable papel de la fotografía en la construcción social de la infancia y la escuela, pues si bien la gran mayoría de la población ha transitado por ambas, en la vida adulta y alejada de la escuela, los conocimientos que se tienen acerca de lo que está sucediendo con una (la infancia) y con la otra (la escuela), se logra en buena medida a través del encuentro con las imágenes que circulan y desde las cuales es posible recrear los discursos $\mathrm{y}$ realidades que las incluyen.

\section{Referencias}

Alonso-Riveiro, M. (2015). La invención de la familia: supervivencia, anacronismo y ficción en la fotografía familiar del primer franquismo. Espacio, Tiem- 
po y Forma, 3, 163-189. http://revistas.uned.es/index.php/ETFVII/article/view/12985 [Consultado el 4 de febrero de 2017].

Amaro, L.; Arecheta, G. (2014). Modernización y experiencias de infancia en la narrativa chilena de la primera mitad del siglo XX. Confluencia, 29(2), 4960. https://www.jstor.org/stable/43490033? seq=1/subjects [Consultado el 6 de marzo de 2019].

Ardren, T.; Hutson, S. (Eds.). (2006). The Social Experience of Childhood in Ancient Mesoamerica. Colorado, EEUU: University Press of Colorado.

Ares-Queija, B. (2007). Los niños de la conquista (Perú, 1532-1560). En P. Rodríguez y M. E. Mannarelli (Eds.). Historia de la Infancia en América Latina (pp. 83-105). Bogotá, Colombia, Universidad Externado de Colombia.

Ariès, P. (1987). El niño y la vida familiar en el Antiguo Régimen. Madrid, España: Taurus.

Ball-llatinas, P. J. (2011). Pedagogía de la mirada y modos de ver. Formar docentes para educar la mirada. Ser Corporal, 5, 19-31. http://revistasercorporal5ped.blogspot.com/2011/04/pedagogia-de-la-mirada-y-modos-dever.html [Consultado el 10 de marzo de 2017].

Baxter, J. E. (2008). The Archaeology of Childhood. Annual Review of Anthropology, 37, 159-175. https://www.annualreviews.org/doi/abs/10.1146/ annurev.anthro.37.081407.085129 [Consultado el 14 de octubre de 2017].

Benjamin, W. (1987). Infancia en Berlín hacia 1900. Buenos Aires, Argentina: Alfaguara.

Benjamin, W. (1989). Escritos: la literatura infantil, los niños y los jóvenes. Buenos Aires, Argentina: Nueva Visión.

Benjamin, W. (2004). Sobre la fotografía. Madrid, España: Pre-textos.

Borrás, J. M. (2010). Fotografía/monumento. Historia de la infancia y retratos postmortem. Hispania. Revista Española de Historia, 70(234), 101136. http://hispania.revistas.csic.es/index.php/hispania/article/viewFile/159/154: [Consultado el 5 de febrero de 2017]. 
Burke, P. (2006). ¿Qué es la historia cultural? Barcelona, España: Paidós.

Burck, M. S. (2009). Estudios visuales e imaginación global. Antípoda, 9, 1946. http://www.scielo.org.co/pdf/antpo/n9/n9a02.pdf [Consultado el 10 de septiembre de 2017].

Cárdenas, Y. (2012). Infancia, juegos y juguetes: contribuciones a un análisis histórico-cultural de la educación en Colombia (1930-1960). Pedagogía y Saberes, 37, 25-36. https://doaj.org/article/b9925bob2a1f43b9a04f4895255b8d97?gathStatIcon=true [Consultado el 7 de agosto de 2017].

Cardona-Quitián, H. E. (2014). El divino niño: Coordenadas para la comprensión de la infancia en la contemporaneidad. Affectio Societatis, $11(20), 12-$ 31. http://aprendeenlinea.udea.edu.co/revistas/index.php/affectiosocietatis/article/view/18308/15733 [Consultado el 9 de febrero de 2017].

Carli, S. (2011a). La representación y narración de la infancia. La obra plástica de Antonio Berni. En I. Cosse (Ed.). La memoria de la infancia Estudios sobre historia, cultura y sociedad (pp. 55-76). Buenos Aires, Argentina: Paidós.

Carli, S. (2011b). Infancia, crisis social y memorias culturales. Las fotografías de fines del siglo XX. La memoria de la Infancia. Estudios sobre historia, cultura y sociedad (pp.165-192). Buenos Aires, Argentina: Paidós.

Comas, F.; Sureda, G. (2016). Album photographique scolaire, histoire et configuration de l'identité des établissements scolaires: le cas du collège Sant Josep Obrer de Palma. Theory and History of Education, 17, 119-140. https://ojs.library.queensu.ca/index.php/encounters/article/view/6302 [Consultado el 17 de febrero de 2018].

Corsaro, W. (1997). The Sociology of Childhood. New York, EE UU: SAGE Publications, Inc.

De Certeau, M. (1996). La invención de lo cotidiano: artes de hacer. Bogotá, Colombia: Universidad Iberoamericana

De Freitas, T. (2015). Los fragmentos de la cultura escolar: una mirada sobre las fotografías de las escuelas primarias públicas en el Estado de Rio Grande do Sul/Brasil (1924). Actas del XVIII Coloquio de Historia de la Educación: 
Arte, literatura y educación (pp. 357-367). Catalunya, España: Universitat de Vic-Universitat Central de Catalunya.

Del Castillo-Troncoso, A. (2006). Conceptos, imágenes y representaciones de la niñez en la ciudad de México, 1880-1920. México, D. F.: Colegio de México.

Del Castillo-Troncoso, A. (2007). Infancia y revolución. Imágenes y representaciones de la niñez en México en las primeras décadas del XX. En P. Rodríguez; M. E. Mannarelli (Eds.). Historia de la Infancia en América Latina (pp. 445-457). Bogotá, Colombia: Universidad Externado de Colombia.

De Maus, L. (1982). Historia de la infancia. Barcelona, España: Alianza.

Díaz-Barriga, A. (2012). La representación social de la infancia mexicana a principios del siglo XVI. En S. Sosenski; Jackson, E. (Eds.). Nuevas miradas a la historia de la infancia en América Latina. Entre prácticas y representaciones (pp. 23-62). México, D. F.: IIH UNAM.

Díaz-Barriga, A. (2013). Ritos de paso de la niñez nahua durante la veintena de Izcalli. Estudios de cultura náhuatl, 46, 199-221. http://www.scielo.org.mx/ pdf/ecn/v46/v46a6.pdf [Consultado el 18 de febrero de 2018].

Donoso, C. (2007). Retrato hablado: la austera visualidad de los relatos de Nellie Campobello. Revista de crítica literaria latinoamericana, 33(66), 173186. https://pdfs.semanticscholar.org/e438/29d651520568ac102eof2fba1 12b7d866950.pdf [Consultado el 11 de noviembre de 2017].

Duek, C. (2012). El juego infantil contemporáneo: medios de comunicación, nuevas prácticas y clasificaciones. Revista Brasileira de Ciências do Esporte, 34(3), 649-664. http://www.scielo.br/pdf/rbce/v34n3/v34n3a09. pdf [Consultado el 20 de septiembre de 2017].

Dussel, I. (2006). Educar la mirada: Reflexiones sobre una experiencia de producción audiovisual y de formación docente. En I. Dussel y D. Gutiérrez (Comps.). Educar la mirada. Políticas y pedagogías de la imagen (pp. 277294). Buenos Aires, Argentina: Manantial.

Dussel, I. (2009). Escuela y cultura de la imagen: los nuevos desafíos. Nómadas, 30, 180-193. http://www.scielo.org.co/pdf/noma/n30/n30a14.pdf [Consultado el 7 de enero de 2018]. 
Gaitán, L. (2006). La nueva sociología de la infancia. Aportaciones de una mirada distinta. Política y Sociedad, 43(1), 9-26. https://revistas.ucm.es/index. $\mathrm{php} / \mathrm{POSO} /$ article/view/POSO0606130009A/22625 [Consultado el 20 de marzo de 2017 ].

Guerrero-Valenzuela, C. (2010). La antropofagia como rito final de la infancia en el regreso de Efraín Barquero. Revista chilena de literatura 77, 75-94. https://scielo.conicyt.cl/pdf/rchilite/n77/arto4.pdf [Consultado el 15 de agosto de 2017].

James, A.; Prout, A. (1997). Constructing and reconstructing Childhood. Contemporary Issues in the Sociological Study of Childhood. Londres, Inglaterra: Falmer Press.

Jenkis, C. (1982). The Sociology of Childhood: Essential Readings. Londres, Inglaterra: Gregg Revivals.

Jiménez, A. (2012). Imaginario y memoria religiosa en Bogotá. Antropología Experimental, 12(14), 175-192. https://revistaselectronicas.ujaen.es/index. $\mathrm{php} / \mathrm{rae} / \mathrm{article} / \mathrm{view} / 1861 / 1613$ [Consultado el 18 de mayo de 2017].

Kritki, J.; Andrea, G. (2014). La función crítica de la fotografía: por una pedagogía de la mirada. (Tesis de postgrado). Universidad de Chile, Santiago, Chile. http://repositorio.uchile.cl/handle/2250/116824 [Consultado el 5 de agosto de 2017].

Londoño P.; Londoño, S. (2012). Los niños que fuimos: huellas de la infancia en Colombia [Exposición]. Bogotá, Colombia: Banco de la República.

Maciá-Barber, C. (2013). Ética, fotoperiodismo e infancia: Imagen del conflicto palestino-israelí en España. Cuadernos. info, 33, 89-98. https://scielo.conicyt.cl/pdf/cinfo/n33/arto8.pdf [Consultado el 5 de agosto de 2017 ].

Marín, E. G.; Restrepo, L. V. (2002). Estado del arte sobre fuentes documentales en investigación cualitativa. Medellín, Colombia: Universidad de Antioquia.

Muñoz, C.; Pachón, X. (1988). Gamines: testimonios. Bogotá, Colombia: Círculo de Lectores.

Muñoz, C.; Pachón, X. (1991). La niñez en el siglo XX. Bogotá, Colombia: Planeta. 
Muñoz, C.; Pachón, X. (1996). La aventura infantil a mediados de siglo: los niños colombianos enfrentan cambios sociales, educativos y culturales que marcarán su futuro. Bogotá, Colombia: Planeta.

Muñoz, C.; Pachón, X. (2002). Réquiem por los niños muertos. Bogotá, Colombia: Centro de Estudios de la Realidad Colombiana.

Ortiz, C. (2006). Una lectura antropológica de la fotografía familiar. En Cuartas jornadas Imagen, cultura y tecnología (pp. 153-156). Madrid, España: Universidad Carlos III.

Ridao, A.; Montenegro, A. (2014). Juego, juguetes e historicidad. Campo de investigación y de intervención. Espacios en blanco. Serie indagaciones, 24(1), 11-16. http://www.redalyc.org/pdf/3845/384539806002.pdf [Consultado el 15 de abril de 2017].

Riego, B. (1999). La imagen de la infancia en la fotografía del siglo XIX. Peonza: Revista de literatura infantil y juvenil, 50, 31-36. http://www.cervantesvirtual.com/servlet/SirveObras/13516176547351507976613/imaO026.htm [Consultado el 8 de marzo de 2017].

Robledo, B. H. (2007). El niño en la literatura infantil colombiana. En Rodríguez, P. y Mannarelli, M. E. (Eds.). Historia de la Infancia en América Latina (pp. 633-648). Bogotá, Colombia: Universidad Externado de Colombia.

Rodríguez, P. (2007). Los hijos del sol: un acercamiento a la infancia de América prehispánica. En Rodríguez, P. y Mannarelli, M. E. (Eds.). Historia de la Infancia en América Latina (pp. 27-70). Bogotá, Colombia: Universidad Externado de Colombia.

Sanchidrián, B. C. (2011). El uso de imágenes en la investigación histórico-educativa. Revista de Investigación Educativa, 29(2), 295-309. https://revistas. um.es/rie/article/view/112691/135271 [Consultado el 17 de octubre de 2017 ].

Sontag, S. (2003). Ante el dolor de los demás. Bogotá, Colombia: Alfaguara.

Sosenski, S. (2012). Producciones culturales para la infancia mexicana: los juguetes (1950-1960). Relaciones. Estudios de historia y sociedad, 33(132), 95- 
128. http://www.scielo.org.mx/pdf/rz/v33n132/v33n132a4.pdf [Consultado el 15 de julio de 2017].

Soto, V. J.; Pérez, P. R. (2017). La producción fotográfica escolar de Ezequiel Fernández Santana 100 años después (1915-2015). Revista Historia de la Educación Latinoamericana, 19(29), 271-302. https://revistas.uptc.edu.co/ index.php/historia_educacion_latinamerican/article/view/7579/5949 [Consultado el 14 de marzo de 2018].

Van-Leeuwen, T.; Jaworski, A. (2002). The Discourses of War Photography: Photojournalistic Representations of the Palestinian-Israeli War. Journal of Language and Politics, 1(2), 255-275. https://www.ingentaconnect. $\mathrm{com} /$ content/jbp/jlp/2002/00000001/00000002/art00005 [Consultado el 20 de julio de 2017].

Villa, N. (2015). La historia de la educación desde la fotografía escolar: recuerdos y ausencias (1900-1970). Actas del XVII Coloquio de Historia de la Educación: Arte, literatura y educación, 2, 462-478. https://dialnet.unirioja.es/servlet/ articulo?codigo $=5207510$ [Consultado el 4 de diciembre de 2017].

Villegas, C. E. (2012). Infancia y fotografía en Antioquia aproximaciones desde la historia socio-cultural. Revista Universidad EAFIT, 34(112), 9-16. http://publicaciones.eafit.edu.co/index.php/revista-universidad-eafit/article/view/1093 [Consultado el 4 de diciembre de 2017].

Viñao-Frago, A. (2012). La historia material e inmaterial de la escuela: memoria, patrimonio y educación. Educação, 35(1), 7-17. http://revistaseletronicas. pucrs.br/ojs/index.php/faced/article/view/10351 [Consultado el 27 de diciembre de 2017].

Zubero, B. I. (2016). Espectadores del dolor ajeno: una imagen no vale más que mil palabras. Revista de estudios sociales, 57, 89-99. http://www.scielo.org. $\mathrm{co} / \mathrm{pdf} / \mathrm{res} / \mathrm{n} 57 / \mathrm{n} 57 \mathrm{a08}$.pdf [Consultado el 9 de febrero de 2018]. 